\title{
Bandwidth Prediction for Business Requirement of Electric Power Communication Network with Deep-Learning
}

\author{
Dong Wang* \\ Information and Communication Branch, State Grid Shanxi Electric Power Company, No.71 Fudong \\ Street,Taiyuan 030000, China \\ 525492887@qq.com \\ *corresponding author
}

Keywords: Electric power communication network, Bandwidth prediction, Deep learning, Principal component analysis, Affect system data.

\begin{abstract}
With the power-supply system information management, it puts forward higher requirement about network bandwidth. Power communication network bandwidth predictive based on business requirement not only ensures smooth of communication, but also is the key technology of enhancing broadband usage. The paper relying on the province power company as the background, analyses the demands of original and new business based on choosing some typical business. By using principal component analysis (PCA), simplifies the affect system data of bandwidth prediction. Simultaneously, using RBM model based on deep learning predicts the bandwidth of power business requirement. It may give the reference for the next stage network construction of Power Company.
\end{abstract}

\section{Introduction}

With extensive secondary equipment in the power grid access, in the past a single point to point communication methods cannot satisfy the development of the existing electric power communication network intelligent power grid and the application of centralized deployment also makes the grid scheduling marketing management growing business needs [1], a single rely on traffic statistics cannot meet the needs of existing business for transmission network and transmission equipment.[2] Therefore, according to the different way of carrying classifying electric power business, at the same time according to the different types of business requirements to its communication broadband traffic prediction, can effectively solve the network congestion, improve the utilization rate of power network. [3]

\section{Existing Power Communication Network Business Analysis}

According to the loading mode, the existing power communication network business can be divided into three categories: dedicated line communication, dispatching data network and integrated data network.

\subsection{Special line communication business}

Business is mainly refers to the power line communication special optical fibre transmission network carrying business, especially power system line communications business, point-to-point special fibre channel, as the core business of power grid safe and stable operation is necessary. For example, dispatching telephone, power system relay protection, remote protection of power system, safe and automatic transposition, etc. [4]. The main function is the remote protection and the security and stability control signal transmission. 


\subsection{Data comprehensive network business}

Data comprehensive web hosting service purpose is to provide service for the production management, scope of business include the following: company business enterprise management information, substation images/communication machine room equipment monitoring system, video conference system, dispatching management information system. [5] This business has a high requirement for signal transmission performance/security and signal transmission reliability, and the transmission delay requirement is lower than that of dedicated line communication business. Therefore, it is necessary to provide reliable transmission paths and adequate broadband.

Existing province electric power communication network traditional business category--five typical business system for telecommunication broadband prediction model to model, analyse network bandwidth requirements, at the same time it is also the foundation of new business bandwidth prediction.

\section{Prediction of Broadband Demand for PCN Based on Deep Learning}

Considering the existing electric power communication network load business variety, large amount of real-time data, simple shallow learning algorithm for the broadband traffic predict with great accuracy, not to waste a lot of broadband traffic data at the same time. In order to improve the accuracy of broadband communication network traffic prediction, qualitative quantitative judgment broadband demand, this paper selects the deep learning method, in view of the province electric power communication network based on the five typical business forecast model, comprehensive analysis and prediction model as a result, the predicted province electric power company the next phase of the broadband demand, at the same time to take into account the special demand for broadband business, such as Internet access business, FTP operations, video voice business, etc.

The pre-training process of deep learning is an unsupervised learning process, and the pretraining network can obtain the initial weight of the algorithm, and the greedy optimization is optimized to its training strategy. The visible layer of RBM is the hidden layer and the inner nodes are opposite each other, and all inter-layer nodes are connected to each other. The energy function and probability distribution function of RBM stochastic model are as follows:

$$
\begin{gathered}
E(v, h, \theta)=-a^{T} v-b^{T} h-v^{T} w h=-\sum_{i \in V} a_{i} v_{i}-\sum_{i \in h} b_{i} h_{i}-\sum_{i, j} v_{i} h_{i} \omega_{i j} \\
p(v, h, \theta)=\frac{1}{Z} e^{-E(v, h, \theta)}
\end{gathered}
$$

Where, $v_{i}$ is visible layer node state. $\mathrm{Hi}$ is hidden node state. $a_{i}$ and $b_{i}$ are the corresponding layer node bias. $\omega_{i j}$ are are the connection weights between nodes. $\theta=\{W, a, b\}$ are network weights, which are parameters that need to be optimized at this stage. $\mathrm{Z}$ is the normalized coefficient, whose expression is as follows:

$$
Z=\sum_{V, h} e^{-E(v, h, \theta)}
$$

On the basis of the maximum likelihood of fitting the input data, the maximum likelihood learning rule can be used to maximize all the input. A fast approximation algorithm is used to train the gradient in the maximization process and reconstruct the weight of RBM. Its weight updating strategy is as follows:

$$
\begin{aligned}
& \omega_{i j}=\varepsilon^{*}\left\{\left(V_{i} h_{i}\right)_{\text {data }}-\left(v_{i} h_{i}\right)_{\text {recon }}\right\} \\
& a_{i}=\varepsilon^{*}\left\{\left(V_{i}\right)_{\text {data }}-\left(V_{i}\right)_{\text {recon }}\right\} \\
& b_{i}=\varepsilon^{*}\left\{\left(h_{i}\right)_{\text {data }}-\left(h_{i}\right)_{\text {recon }}\right\}
\end{aligned}
$$

Where, $\varepsilon$ is the vector. $(*)_{\text {data }}$ are sample expectations. ${ }^{(*)_{\text {recon }}}$ are RBM Re-factoring expectations. 


\section{Simplified Analysis of the Influence Index of Broadband Prediction Based on Principal Element Analysis}

Principal component analysis method is one of common methods of multivariate statistical analysis, is to a certain dependency relationship $\mathrm{N}$ parameters $\mathrm{M}$ array based on a sample of data, through the establishment of a smaller number of variables, to make it more concentrated reflect the change of $\mathrm{N}$ parameters contained in the original information. The main element analysis method is used to simplify the data of the influencing factors of the power communication broadband forecast. The specific implementation process is as follows:

1) The initial matrix of historical data to obtain the influence factors of broadband prediction.

2) Calculate the correlation coefficient matrix of the initial matrix, and its equation is as follows:

$$
R=\left[\begin{array}{ccc}
r_{11} & \cdots & \\
\vdots & \ddots & \vdots \\
& \cdots & r_{n m}
\end{array}\right]
$$

Where $r_{i j}$ is the i row j column data of the correlation coefficient matrix.

3) The characteristic roots and eigenvectors of the correlation coefficient matrix are calculated.

4) The cumulative contribution rate of the first q primary element is calculated, and the corresponding $\mathrm{q}$ is the pre-q principal component extracted.

$$
G(q)=\sum_{i=1}^{q} \lambda_{i} / \sum_{k=1}^{m} \lambda_{k}
$$

5) The main element of the influence factor system of wide-band prediction is written according to the principal element coefficient matrix, and then the influence factor system data of communication broadband forecast is simplified.

\section{Experimental Results and Analysis}

The remaining existing business flow prediction model and the development of new business models are based on the above five typical business system. More business flow prediction model fitting together, to be able to predict the province level 4 integrated data network broadband network communication demand, in the business management information, video conference/voice business, Internet business, for example, one day forecast flow will be predicted using the algorithm of matter flow results comparing with the traditional BP neural network prediction results, the result as shown in table 1.

Table 1 The results of the prediction of electric power communication network requirement.

\begin{tabular}{|c|c|c|c|c|c|c|c|c|c|c|}
\hline \multirow{2}{*}{ No } & & \multicolumn{3}{|c|}{ Business type demand network communication broadband (M) } \\
\cline { 3 - 12 } & Link Business & \multicolumn{2}{|c|}{$\begin{array}{c}\text { Management } \\
\text { information }\end{array}$} & \multicolumn{2}{c|}{$\begin{array}{c}\text { Video } \\
\text { conference/voice }\end{array}$} & \multicolumn{3}{|c|}{ Internet service } \\
\cline { 3 - 12 } & RBM & BP & AF & RBM & BP & AF & RBM & BP & AF \\
\hline 1 & $\begin{array}{c}\text { Main integrated data } \\
\text { network }\end{array}$ & 1420 & 1350 & 1500 & 187 & 210 & 200 & & & \\
\hline 2 & $\begin{array}{c}\text { Provincial-level } \\
\text { integrated data network } \\
\text { (uplink) }\end{array}$ & 285 & 241 & 310 & 88 & 81 & 86 & 589 & 635 & 600 \\
\hline 3 & $\begin{array}{c}\text { Regional integrated data } \\
\text { network (branch up) }\end{array}$ & 42 & 30 & 35 & 4.9 & 5.7 & 5.5 & 74 & 84 & 78 \\
\hline 4 & $\begin{array}{c}\text { Regional integrated data } \\
\text { network }\end{array}$ & 3.9 & 3.5 & 4.5 & 2 & 2.2 & 1.7 & 5.1 & 6 & 6.5 \\
\hline
\end{tabular}

Using RBM prediction algorithm and traditional BP neural network prediction, the following conclusions are drawn:

Compared with the BP neural network, in this paper, prediction model of broadband communication network traffic prediction error is low, the prediction precision is improved, is 
mainly due to the deep learning method can make use of more historical data sample fitting curve, improve the prediction accuracy, and at the same time compared to county - the broadband traffic prediction error, the trunk integrated broadband data network prediction accuracy is higher, is due to the prediction model based on deep learning its input data, the prediction precision is higher. Therefore, this paper constructs a better forecast model of power communication broadband traffic.

\section{References}

[1] An J Y. Theory development in health care informatics: Information and communication technology acceptance model (ICTAM) improves the explanatory and predictive power of technology acceptance models. Studies in Health Technology \& Informatics, 122:63-67.

[2] SajdaQureshi. Networks of change, shifting power from institutions to people: how are innovations in the use of information and communication technology transforming development. (2013), Information Technology for Development, 19(2):97-99.

[3] Laitner J A, Ehrhardt-Martinez K. Information and communication technologies: The power of productivity (Part II). (2009), Environmental Quality Management, 18(3):19-35.

[4] Yigit M, Gungor V C, Tuna G, et al. Review Article: Power line communication technologies for smart grid applications: A review of advances and challenges. (2014), Computer Networks the International Journal of Computer \& Telecommunications Networking, 70(10):366-383.

[5] Wang W, Xu Y, Khanna M. A survey on the communication architectures in smart grid. (2011), Computer Networks, 55(15):3604-3629. 